\title{
An Evaluation of Stable Gel Systems for Deep Injector Treatments and High Temperature Producer Treatments
}

\author{
* Kvanvik B. A., * Kolnes J., * Tyvold T., ** Olafsen K., \\ * Nilsson S., * Matre B., * Skjellerudsveen B. \\ * RF - Rogaland Research, Norway \\ ** Sintef, Norway
}

\begin{abstract}
Copyright 1995, Steering Committee of the European IOR - Symposium.
This paper was presented at the 8th. European IOR - Symposium in Vienna, Austria, May 15 - 17,1985

This paper wes selected for presentation by the Steering Committee, tollowing review of information conteined in an abatract

aubmitted by the author(s). The paper, as presented has not been reviewed by the Steering Committee.
\end{abstract}

\begin{abstract}
This paper presents a summary of the activity on gel in the Norwegian RUTH (Reservoir Utilisation through advanced Technological Help) research program. RUTH is a four year research program, started in 1992. The objectives of the gel subprogram have been to:

- Identify and characterise stable gel systems with

flexibility in terms of gelation time. The gel

systems should fulfil the criteria set for:

- deep injector treatments.

- high temperature producer treatment.
\end{abstract}

- Prepare for a field application (pilot test).

In this work protecting ligands on the crosslinker have been used to obtain a delayed gelation rate. and a large number of gel systems have been evaluated regarding gelation rate. Both protected covalent crosslinkers and metal complex crosslinkers (metal complex ligand system based on chromium, aluminium, titanium and zirconium) are examined. Several of these gel systems are tested for thermal stability up to $120^{\circ} \mathrm{C}$ under anaerobic conditions, both in bulk and in sand pack and coreflood experiments.

The retention is particularly important for in-dept systems and generally it is the crosslinker retention that can cause severe problems. The retention mechanisms have been thoroughly examined for several of the protected crosslinkers. The retention is found to be strongly dependent on the core material used and $\mathrm{pH}$ (due to precipitation of the crosslinker at cerain $\mathrm{pH}$ levels).

Correct placement is crucial for success for a treatment. and placement issues are discussed. A correct placement often requires a gelant with high mobility (particularly for deep diverting gel systems). Therefore most of the work is performed using low concentrations of polymer or polymers with low molecular weight.

The work in the RUTH gel subprogram has included an evaluation of a gel pilot candidate on the Gyda field. Two pilot studies will be performed in 1995, on two different North Sea reservoirs.

\section{Introduction}

As the fields become more mature, there will be an increasing challenge to improve the productivity of high water-cut wells. The water production problems can have several origins, and a large number of options and processes for reducing water-cut exist. Gel technology is characterised by rather small quantities of chemical and specially for producer treatments. short payback time. It will most probably be profitable to apply gels in suitable reservoirs even at rather low oil price.

Recently Seright ${ }^{1}$ published a survey of field activity for gel treatments in injector and producer wells. The survey covered the period from 1980 until 1992 for injector treatments and from 1970 to 1991 for producer treatment. The survey included 114 injector gel projects and 274 field cases of producer treatment. Seright found that during the past 15 years. the chromium(VI)-redoxHPAM process has been used most frequently by vendors in both injection and production wells. Other gelants that were often used by vendors in injection wells included aluminium-ciuate-HPAM/CPAM (by EPT and Tiorco), silicate. acrylamide monomer (by

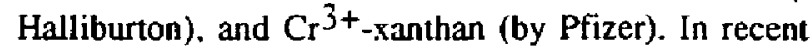
years, glyoxal-CPAM gels have been applied frequently in production wells (by Pfizer), and $\mathrm{Cr}^{3+}$ (acetate)HPAM gels have recently become popular for injector applications. 
Gel systems with delayed gelation rate can be very useful for several applications:

- Large volume (or in-depth) matrix treatments of injectors.

- Treatment of producers in high temperature reservoirs.

- Large volume (or in-depth) matrix treatment of producers to prevent coning of water or gas.

- Improved tendency of selective placement in reservoirs with viscous oil.

In the literature several techniques are described that can delay the gelation rate. Commonly the delayed gelation rate is achieved by:

- Generating the crosslinking species by a slow chemical reaction, as for the reduction of dichromate into $\mathrm{Cr}^{3+}$

- A compound is slowly liberated which is a caralyst for the gel formation.

- Protecting the crosslinking species by a complexing agent as in chromium acetate or aluminium citrate or by protecting the reactive group on the crosslinker.

- Gelation rate controlled by rate of polymer hydrolysis.

In recent years. much research has been carried out to find and characterise complexing additives for $\mathrm{Cr}^{3+}$ which delays the gelation rate $2-7$.

Several different gel forming systems using organic crosslinking exist, as reviewed by Moradi-Araghi et al. ${ }^{8}$ One organic system commonly used is the acrylamidephenol and formaldehyde system. The gelation time for acrylamide-phenol and formaldehyde systems are relative insensitive to the concentration of phenol and formaldehyde or $\mathrm{pH}$. The gelation rate is mainly controlled by temperature and the nature of the polymer. One problem with this system is that phenol can partitionate into crude oil ${ }^{9}$. Moradi-Araghi 10 reported that slowly reacting and stable gels at elevated temperatures could be formed using hexamethyleneteramine (HMTA) as crosslinker. HMTA thermally hydrolysis to formaldehyde and ammonia at elevated temperatures and gel can be formed with acrylamide containing polymer and phenol (or using suitable substitutes for phenol).

\section{Gel system selection criteria}

In recent years there has been an increased interest for applying the gel technology on a larger scale to increase sweep efficiency. Such a deep emplacement or large volume treatment will require a number of conditions to be fulfilled by the injected gelant:

- Environmental benign

- Slow gelation rate

- Low retention
- High gelant mobility and good injectivity.

- Robustness (e.g. regarding $\mathrm{pH}$ )

- Long term temperature stability

- Low to intermediate gel strength needed. Typically a permeability reduction after trearment less than a factor hundred is sufficient.

- Low chemical costs

- Be available in large quanta

The same list of requirements more or less also applies for treatment of high temperature producers. The most important difference is that a much higher gel strength is normally needed. However, if the gel is to be used in a horizontal producer the gel strength needed can be reduced due to the low drawdown in a horizontal well.

One common requirement set for a producer treatment is that the gel should reduce the effective water relative permeability more than the oil effective relative permeability. In recent years much research has been carried out to understand the behaviour of such gels but this has not been a research topic for the RUTH gel subprogram.

For near well producer treatments, different placement techniques can reduce the requirements of having gel systems with low viscosity or high gelant mobility, as discussed below.

\section{Placement of gel}

Gel treatment failures are commonly caused by wrong placement. Communication between layers with crossflow or communication in the well completion can cause gel to impair oil productive zones even if zone isolation is used. If zone isolation is not effective, a viscous gelant will penetrate to a greater extent into low permeable zones than a high mobility gelant.

High gel strength is normally associated with high polymer concentration. Consequently for producer treatments, viscous gelants with low mobility are commonly used.

The problem of gelant entering low permeable zones can be reduced or even avoided by applying a dual injection technique. A protective pressure fluid (e. g. diesel or water) is injected down the coiled tubing annulus during gelant injection. The protective pressure fluid will prevent the gelant to enter into the zones to be protected 11,12 . This dual injection can also be performed using parailel-tubing 13 .

Use of coiled tubing and zone isolation increases the cost of the treatment and this technique is not al ways possible. For some wells the only alternative is to use bullhead injection, Liang and Seright ${ }^{14}$ claimed that a capacity to reduce water permeability much more than oil permeability is critical for the success of gel treatments if zones cannot be isolated during gel placement. However, we propose a placement method for bulthead injection were this not necessarily is true 
(However it would still be an advantage having such a system).

The idea of the proposed placement method for producer wells in high temperature reservoirs is to take advantage of the high temperature. The first step is to generate a uniform temperature front some distance away from the wellbore. This uniform temperature front can be achieved by using a viscous and cold pre flush (e.g. by adding a polymer that will not form gel with the crosslinker). The method also require that a highly mobile gelant is used. When the gelant is injected, it fingers down the high permeable layer. It quickly hits the hot zone, and gels. Then injection is stopped, and the well is returned to production before any gelant in the low permeable zone has reached the hot zone. A similar approach has earlier been suggested by Morgan 11 , but with somewhat different technique to obtain the uniform temperature front. Morgan suggested to inject a pre flush of cold water, then to shut-in the well and rely on that conductivity from overlying and underlying layers eliminates the cold finger in the high permeable layer. (As mentioned, the proposed method for bullhead injection requires high mobility gelants, and mainly low concentration systems which have low viscosity are used in this study.)

\section{Experimental}

\section{Polymers used :}

- HPAM: AF 935 and AF 254 from Allied Colloids (with molecular weight of about $7 \cdot 10^{6} \mathrm{~g} /$ mole and $5 \cdot 10^{5} \mathrm{~g} /$ mole, respectively. The degree of hydrolysis is about $10 \%$ and $5 \%$, respectively. Both polymers can be used as MARCIT gels.

- PAM: W 17 from Allied Colloids (less than 1\% hydrolysed and a molecular weight of about $5 \cdot 10^{5}$ ).

- Co- and terpolymer: HE100. HE300 and HE350 from Drilling Specialities Company.

- Xanthan: FLOCON $4800 \mathrm{C}$ with molecular weight of about $3 \cdot 10^{6}, \quad \mathrm{XC} 67$ and $\mathrm{XC127}$ from Biosentrum. Statoil.

- Scleroglucan: Actigum CS11 from Elf Aquitene

- Polyvinyl alcohol (PVA): Floperm 665 P from OFPG Inc.

\section{Metal complex crosslinkers}

The following metals are used:

- Chromium: Chromium nitrate $\left[\mathrm{Cr}_{3}\left(\mathrm{NO}_{3}\right)_{3} \cdot 9 \mathrm{H}_{2} \mathrm{O}\right]$ and chromium chloride $\left[\mathrm{CrCl}_{3} \cdot 6 \mathrm{H}_{2} \mathrm{O}\right]$ from Merck and from Aldrich. Chromium acetate [ $\left.\mathrm{Cr}\left(\mathrm{CH}_{3} \mathrm{COO}\right)_{3}\right]$ from McGean-Rohco Inc., containing $0.8 \mathrm{wt}^{3} \mathrm{Cr}^{3+}$

- Aluminium: Aluminium chloride $\left[\mathrm{AlCl}_{3} \cdot 6 \mathrm{H}_{2} \mathrm{O}\right.$ ] from Riedel-de Haen.

- Iron: Iron chloride $\left[\mathrm{FeCl}_{3}\right]$ from Fluka
- Titanium: TYZOR La Titanate from Du Pont containing 8.2 wt\% titanium.

- Zirconium: TEAZ from Huls AG containing 13-15 wt\% zirconium.

The ligands used to form metal complexes were used in their acid form (table 2), giving a larger number to select from compared to the carboxylate form. The purity of the acids were $99 \%$.

Crosslinkers for crosslinking of $P V A$

- Glutaraldehyde FLOPERM 665 X from Pfizer Inc.

- 2,5-dimethoxy-2,5-dihydrofuran from Fluka

- 2,2'-rimethylene bis-1,3dioxolane from Aldrich.

Crosslinkers for crosslinking of $H E 300$.

- Phenol and formaldehyde from Merck

- Dirnethoxymethane from Janssen Chemica

Brine

Unless else is specified all solutions are prepared in synthetic seawater, table 1 .

Table 1: Composition of synthetic seawater

\begin{tabular}{ll} 
Salt & $\mathrm{g} / 1$ \\
\hline $\mathrm{NaCl}$ & 24.79 \\
$\mathrm{MgCl} \cdot \mathrm{H} 2 \mathrm{O}$ & 11.79 \\
$\mathrm{KCl}$ & 0.80 \\
$\mathrm{CaCl}_{2} \cdot \mathrm{H}_{2} \mathrm{O}$ & 1.60 \\
$\mathrm{SrCl}_{2} \cdot \mathrm{H}_{2} \mathrm{O}$ & 0.021 \\
$\mathrm{Na}_{2} \mathrm{SO}_{4}$ & 4.14 \\
$\mathrm{NaHCO}_{3}$ & 0.206
\end{tabular}

\section{Results}

\section{Metal Complex Crosslinkers}

Conway and co workers ${ }^{15}$ found that iwenty-two different metal ions could be used to crosslink watersoluble polysaccharides. In addition can several watersoluble synthetic polymers can be crosslinked with various metal ions. Knowing that there exist a large number of components e.g. carboxylic acids capable of complexing chromium. aluminium and other metal ions. it is obvious that the number of possible gel systems is very large.

For our work within metal complex crosslinkers, hydrolysed polyacrylamides (HPAM), co- and terpolymers were chosen as the main polymers. These were selected since:

- They are crosslinkable with both chromium and aluminium

- They are thermally stable 
- HPAM can be modified both regarding molecular weight and degree of hydrolysis.

- co- and terpolymers are compatible with divalent - ions.

\section{Delayed gelation rate}

Search for gel systems with flexibility in terms of gelation time was done by simply adding complexing agents (ligands) to the metal solution. For chromium and malonic acid it was shown by UV-analysis that the complex was formed in less than 2 days at $60^{\circ} \mathrm{C}$ and at pH 5.0.

The idea was that the ligand would protect the metal from fast gelation, retention on core material and from precipitation of the metal hydroxide. Since it is the carboxylate groups on the polymer that reacts with the metal to form crosslinks, it was natural to look among the carboxylic acids for ligands. Table 2 shows the behaviour aluminium crosslinkers at $90^{\circ} \mathrm{C}$, initial $\mathrm{pH}$ of 4 in $3 \% \cdot \mathrm{NaCl}$ brine. The ligand to metal ratio is 3 . Of the 11 acids tested, 4 is too weak to protect against precipitation, citrate is too strong to allow gel formation and 6 ligands gives a gelation time (determined by visual inspection) in the range of 5 to 118 hours. Under similar conditions the gelation time of chromium acetate will be less than half an hour.

Similar observations were obtained for chromium when the same type of ligands where used with chromium. Table 3 shows the gelation time for chromium oxalate for different ligand metal ratios. By increasing ratio from 0.5 to 5 the gelation time can be increased by a factor of 200. Even slower gelation were observed for malonic acid as ligand. It should be noted that oxalic acid is not compatible with seawater due to the precipitation of calcium oxalate. Similar gelation rate dependence on ligand to metal ratio is observed using aluminium.

Table 2: Behaviour of aluminium crosslinkers at $90^{\circ} \mathrm{C}$, initial $\mathrm{pH}$ of 4 in $3 \% \mathrm{NaCl}$ brine. Ligand to aluminium ratio is 3 .

\begin{tabular}{lcc} 
Ligand & $\begin{array}{c}\text { Precipi- } \\
\text { tation }\end{array}$ & $\begin{array}{c}\text { Gelation } \\
\text { time (h) }\end{array}$ \\
\hline Glycolic acid & No & $5-24$ \\
Oralic acid & No & $24-29$ \\
Malonic acid & No & $46-53$ \\
Succinic acid & Yes & \\
Succinamic acid & Yes \\
Etyl-malonic acid & No & $53-73$ \\
Malic acid & No & $73-118$ \\
Butan tetra carboxylic acid & Yes \\
Tricarballylic acid & Yes \\
Tartaric acid & No & $24-29$ \\
Citric acid & No & No gel
\end{tabular}

Table 3: Gelation time for chromium oxalate for "different ligand metal ratios at $80^{\circ} \mathrm{C}$ and a $\mathrm{pH}$ of $5,3 \% \mathrm{NaCl}$.

\begin{tabular}{cc}
$\begin{array}{c}\text { Oxalic acid to } \\
\text { chromium ratio }\end{array}$ & $\begin{array}{c}\text { Gelation time } \\
\text { (hours) }\end{array}$ \\
\hline 0.5 & $0.4-0.7$ \\
1 & $1.6-2.3$ \\
2 & 20 \\
3 & $38-76$ \\
5 & $76-105$
\end{tabular}

Malonic acids were chosen as the ligand for further studies for both aluminium and chromium. The notation used for the complexes is $M L_{X}$, where $M$ is the metal ion. $\mathrm{L}$ is the ligand and $\mathrm{x}$ is the ligand to metal ratio. Hence AlMa4 is aluminium malonate with malonic acid to aluminium ratio of 4 .

Fig 1 shows how the gelation time of $\mathrm{CrMa}_{3}$ / HPAM depends on both $\mathrm{pH}$ and temperature. Here the $\mathrm{pH}$ is kept constant during the experiment by adding $\mathrm{HCl}$ or $\mathrm{NaOH}$ using an autotitrator. Gelation time is the time it takes before the gelant plugs a $5 \mu \mathrm{m}$ Millipore filter.

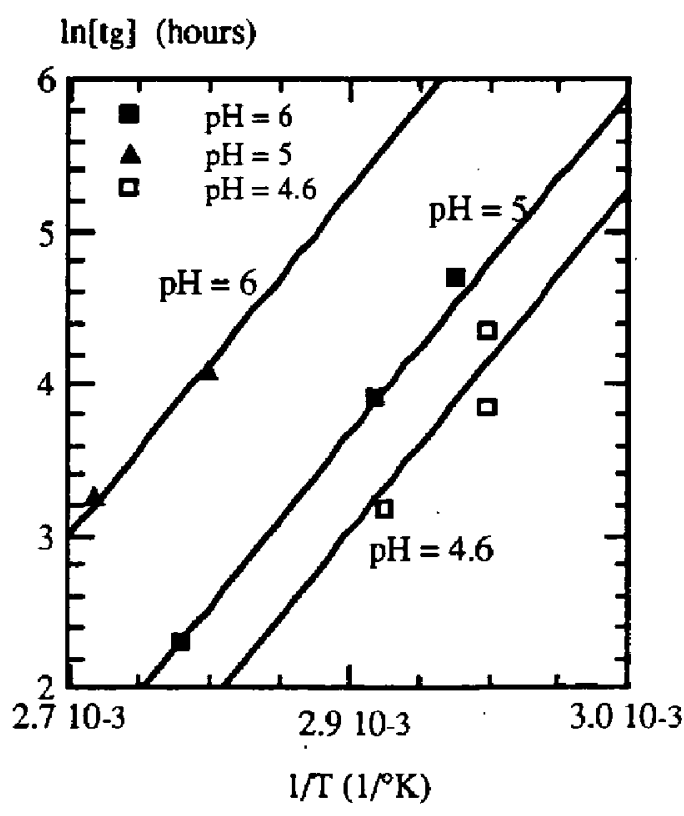

Figure 1: The natural logarithm of the gelation time as a function of the inverse temperature at different $\mathrm{pH}$.

Figure 1 shows that as $\mathrm{pH}$ increases, the gelation time increases. This is opposite of the trend previously observed for chromium acetate or chromium chloride ${ }^{16}$, and is consistent with the proposed theory for the gelation mechanism where decomposition of malonate is suggested as the rate determining step ${ }^{3}$. Since the fully protonised acid is known to decompose faster than the dissociated acid, the rate of decomposition, and gelation. is expected to increase with decreasing $\mathrm{pH}$. Our 
results indicate an increase in gelation rate by a factor of 6 as the pH is decreased by one unit. Increasing the temperature by $10^{\circ} \mathrm{C}$ increases the gelation rate by a factor of 5 . As shown in fig 1 a straight line is obtained if the logarithm of gelation time is plotted against the inverse of the absolute temperature (Arrhenius-like relationship). The lines in figure 1 fit the equation:

$$
\text { In } \mathrm{tg}_{\mathrm{g}}=15000 / \mathrm{T}+1.6 \mathrm{pH}-47.83
$$

where the gelation time $\operatorname{tg}$ is the gelation time in hours and the temperature, $T$. in ${ }^{\circ} \mathrm{K}$. Equation (1) can be used to predict the gelation time as a function of both $\mathrm{pH}$ and temperature. If $\mathrm{pH}$ is not kept constant during gelation, (as in the screening measurements reported in table 1 and 2) the $\mathrm{pH}$ can increase with more than $1 \mathrm{pH}$ unit during the experiment. This will lead to slower gelation. If accurate gelation time is to be measured the $\mathrm{pH}$ must be kept constant either by titration or by a buffer, if the buffer used not affects the gelation process.

Besides the work with. HPAM, some studies have been performed using xanthan and scleroglucan as polymers. Xanthan failed to form gel with CrMa3 as crosslinker. One possible explanation is that precipitation of chromium is faster than gelation. Scleroglucan were crosslinked using both zirconium and titanium. However the minimum polymer concentration that resulted in gelation had too high a viscosity for a deep placement process.

\section{Retention and gelation in cores.}

A large number of retention and gelation experiments have been performed using sand packs. Berea and Bentheimer cores (details can be found elsewhere Stavland and Nilsson ${ }^{6}$ ).

At room temperature the retention of $\mathrm{CrMa}_{3}$ in Berea at a pH of 5 is $3.6 \mu \mathrm{g} / \mathrm{g}$, which is low compared to the retention at similar conditions of $\mathrm{CrCl}_{3}(60 \mu \mathrm{g} / \mathrm{g})$ or $\mathrm{Cr}$-Acetate $(30 \mu \mathrm{g} / \mathrm{g})$. Even at a pH of 7 the retention stays at this low level. As temperature is increased to $80^{\circ} \mathrm{C}$ an increase in retention is observed. At these conditions the effluent chromium concentration is lower than the injected concentration, and after a shut-in time of 1 week no chromium is produced. As temperature is increased we also observe an increase in $\mathrm{pH}$ from 5 to almost 8 . and increased production of calcium and iron. This can be explained if dissolution of calcite $\left(\mathrm{CaCO}_{3}\right)$ and siderite $\left(\mathrm{FeCO}_{3}\right)$ from the core material is assumed. The resulting $\mathrm{pH}$ increase leads to increased retention by precipitation. At high temperatures the precipitation of chromium is caused by degradation of chromium malonate to less soluble chromium acetate and chromium acetate propagates very poorly at elevated temperatures.

Several core experiments have been carried out to test for the ability to form gel in Berea cores. Some of the problems observed are illustrated by the gelation experiment summarised in table 4 and figure 2 . In this experiment the gelant composition was $7.5 \mathrm{mM}$ CrMa3 and $5000 \mathrm{ppm}$ HPAM buffered with $0.1 \mathrm{M}$ acetate to a $\mathrm{pH}$ of 5. Effluent chromium and iron concentrations and $\mathrm{pH}$ were measured at different flow rates. From table 4 we see that $\mathrm{pH}$ increases to 5.9 , and there is considerable production of iron. However the $\mathrm{pH}$ seems to be sufficiently low to prevent significant reduction in chromium concentration, even at a flow rate of 0.07 $\mathrm{ml} / \mathrm{min}$, corresponding to a residence time of 17 hours in the core. This indicates that the crosslinker can be transported efficiently through the core at the slow rates expected in a deep treatment if $\mathrm{pH}$ is lower than 6. After a 25 day shut-in period the $\mathrm{pH}$ had increased to 7.8 . A resistance factor of more than 1000 was measured after shut-in at 21 PV of injected gelant. However, it was verified that this was due to front plugging since the resistance factor after cutting off $1 \mathrm{~cm}$ of the inlet of the core dropped to 1.4. It seems as if $0.1 \mathrm{M}$ of acetate buffer is insufficient to prevent long term precipitation and assure gelation in the Berea core.

Table 4: Effluents from Berea core. Injected $7.5 \mathrm{mM}$ $\mathrm{CrMa}_{3}$ with $0.1 \mathrm{M} \mathrm{HAC}$ and $5000 \mathrm{ppm} \mathrm{AF} 935$ at a pH of 5 .

\begin{tabular}{|c|c|c|c|}
\hline $\begin{array}{c}\text { Rate } \\
(\mathrm{ml} / \mathrm{min})\end{array}$ & $\begin{array}{c}\text { Cr conc. } \\
\text { Relative }\end{array}$ & $\begin{array}{c}\text { Fe conc. } \\
(\mathrm{ppm})\end{array}$ & $\mathrm{pH}$ \\
\hline 2.0 & 0.98 & 32.6 & 5.57 \\
\hline 0.7 & 0.99 & 57.8 & 5.82 \\
\hline 0.2 & 0.99 & 61.2 & 5.80 \\
\hline 0.07 & 0.98 & 53.8 & 5.91 \\
\hline
\end{tabular}

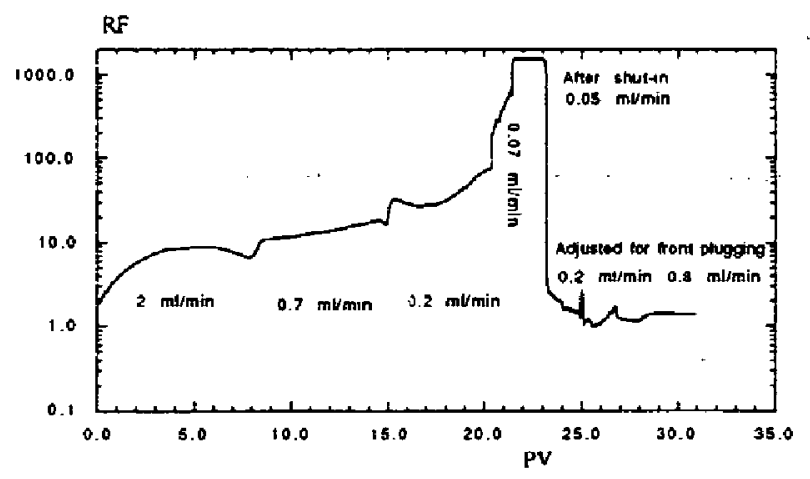

Fig. 2 Mobility reduction during injection of $7.5 \mathrm{mM}$ CrMaz and 5000 ppm HPAM buffered with $0.1 \mathrm{M} \mathrm{HAc}$ and after shut-in for 25 days at $80^{\circ} \mathrm{C}$.

Similar experiments were carried out in Bentheimer cores at initial $\mathrm{pH}$ of 5 and 7 . As an example, table 5 and figure 3 show the results from the experiment at a $\mathrm{pH}$ of 7. Due to the low content of carbonates in the Bentheimer core, the $\mathrm{pH}$ is fairly constant. even without any buffer. After a shut-in period of 10 days a resistance factor of $5 \cdot 10^{4}$ was measured after having corrected for end effects. The same results were obtained at initial $\mathrm{pH}$ of 5 . This shows that gelation is obtained if $\mathrm{pH}$ is kept below 7 . 
Table 5: Effluents from a Bentheimer core. Injecting $7.5 \mathrm{mM}$ CMMás atnd" $6000 \mathrm{ppm}$ AF 935 at $\mathrm{pH} 7$.

\begin{tabular}{|c|c|c|c|}
\hline $\begin{array}{c}\text { Rate } \\
\mathrm{ml} / \mathrm{min}\end{array}$ & $\begin{array}{c}\text { Cr conc } \\
\text { Relative }\end{array}$ & $\begin{array}{c}\text { Fe conc } \\
\mathrm{ppm}\end{array}$ & $\mathrm{pH}$ \\
\hline 2.0 & 0.99 & 0 & 6.95 \\
\hline 0.7 & 0.99 & 0.1 & 6.84 \\
\hline 0.2 & 0.99 & 0.1 & 6.60 \\
\hline 0.07 & 0.99 & 0.1 & 6.66 \\
\hline
\end{tabular}

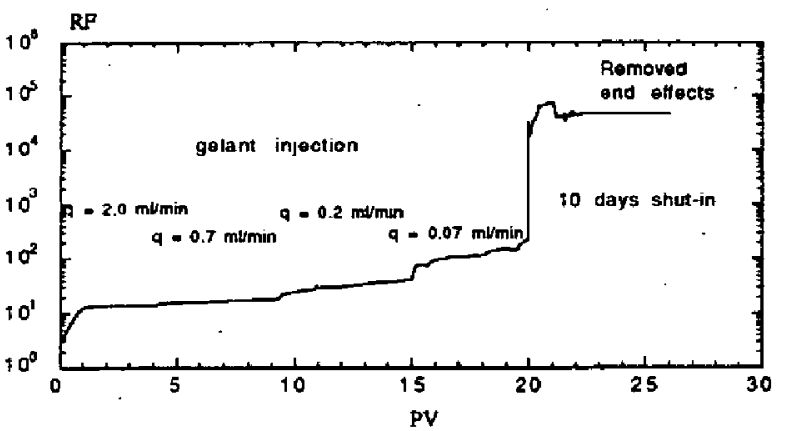

Fig. 3 Mobility reduction in a Bentheim core before and after gelation of $7.5 \mathrm{mM} \mathrm{CrMa3}$ and 6000 ppm HPAM at $\mathrm{pH} 7$.

Further experiments on Berea sandstone with this system have showed that three conditions had to be fulfilled in order form gel in the core:

1) Acetate concentration has to be higher than $0.1 \mathrm{M}$ to keep $\mathrm{pH}$ below 7 after the shut-in period. $0.6 \mathrm{M}$ acetate and an initial $\mathrm{pH}$ of 4.5 is sufficient.

2) Chromium concentration has to be increased due to -ion exchange with the clays. $15 \mathrm{mM}$ is sufficient.

3) The experiments have to be conducted at anaerobic conditions since the presence of iron and oxygen will probably degrade the polymer through the formation of free radicals.

It is expected that condition 1) and 3) will be fulfilled by most sandstone reservoirs. That is a constant $\mathrm{pH}$ below 7 and anaerobic conditions. However, one needs to be careful when performing core experiments with gel systems that have long gelation time. Especially when the cores contain large amount of carbonates and iron. We recommend to perform the retention experiments at reservoir temperalune.

\section{Thermal Stability}

A large number of gel systems have been tested for thermal stability. Different polymers and crosslinkers were tested to be able to select thin gel systems with good injectivity and sufficient gel strength. All gelant system tested did have low initial viscosity, less than 10 $\mathrm{cP}$ at $25^{\circ} \mathrm{C}$. A four step testing procedure has been used.
Phase 1 (Screening phase), The gel systems were tested at $96^{\circ} \mathrm{C}$. The systems were evaluated through measurements of relative filtration time, viscosity, $\mathrm{pH}$ and gel strength described by a bottle gel strength code. Polymer and crosslinker concentrations were varied to determine the optimal concentration range.

Phase2. The most promising gel systems were further tested in bulk experiments for $25-105$ days at $120^{\circ} \mathrm{C}$ and anaerobic conditions, table 6 . Thermal stability was determined by visual inspection of gel strength and the degree of syneresis. The polymer concentrations indicated in table 5 are minimum and maximum concentrations used.

Table 6. Long term stability of selected systems at $120^{\circ} \mathrm{C}$ and anaerobic conditions:

\begin{tabular}{|c|c|c|}
\hline Polymer & $\begin{array}{c}\mathrm{CrAc}_{3} \\
{\left[\mathrm{ppm} \mathrm{Cr}{ }^{3+}\right]}\end{array}$ & $\begin{array}{c}\mathrm{CrMa4}_{4} \\
{\left[\mathrm{ppm} \mathrm{Cr}^{3+}\right]}\end{array}$ \\
\hline $\begin{array}{c}\text { HPAM } \\
(3,000-5,000 \mathrm{ppm})\end{array}$ & $50-100$ & $50-100$ \\
\hline $\begin{array}{c}\text { PAM } \\
(7,500-15,000 \mathrm{ppm})\end{array}$ & $150-750$ & $200-400$ \\
\hline $\begin{array}{c}\text { Terpolymer } \\
(3,500-10.000 \mathrm{ppm})\end{array}$ & $57-500$ & $100-350$ \\
\hline
\end{tabular}

Step 3. Thermal stability in porous media (quarts sand packs) was then evaluated by measurements of residual resistance factor (RRF) at anaerobic conditions and $120^{\circ} \mathrm{C}$, figure 4 . The gelants were all injected into the sand packs at $120^{\circ} \mathrm{C}$. The RRF showed in figure 4 is the permeability reduction in the middle section of the sand pack. This to ensure that it is not only front plugging.

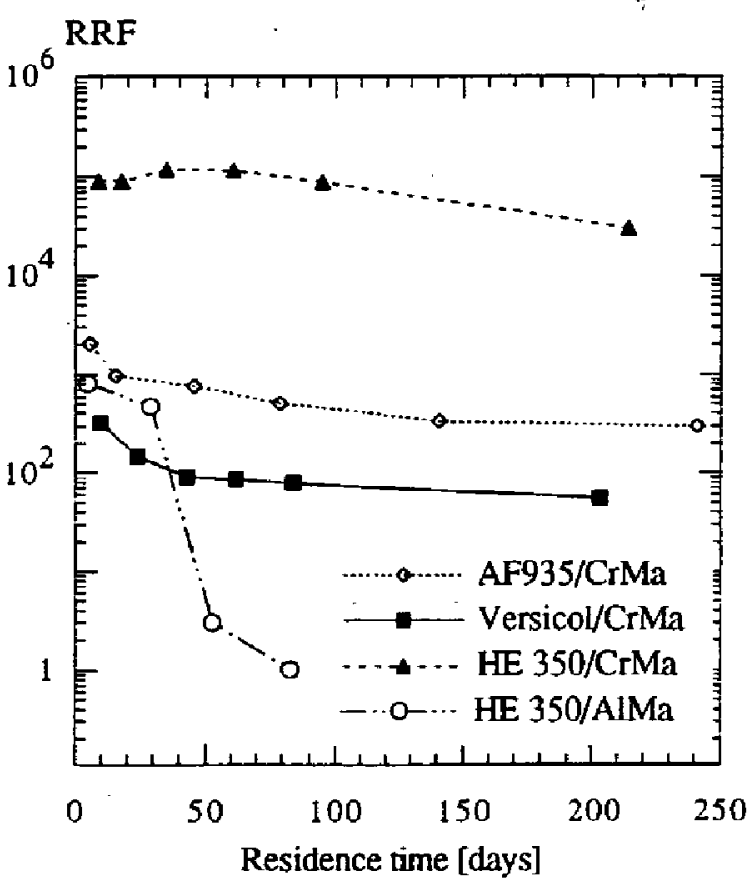

Figure 4: Residual resistance factor in four sand packs treated with thin gel. 
The gels made from HE 350 and $\mathrm{Cr}$-malonate or Almalonate were stable for 84 days regarding syneresis in bulk experiments and the gel system involving $\mathrm{Cr}$ malonate showed a stable RRF of $2.9 \cdot 10^{4}$ for more than 214 days. The $10 \%$ hydrolysed polyacrylamide/Crmalonate gel gave a high degree of syneresis. However, the RRF measured in a sand pack flood was 292 after 241 days.

A gel made from low hydrolysed polyacrylamide/Crmalonate syneresed $40 \%$ in 105 days. The gel strength measured as the yield pressure in a capillary tube, increased with a factor 4 in a period of 105 days and the RRF measured in a sand pack flooding was 54 after 203 days.

Step 4 the most promising systems will also be tested in reservoir cores from North-Sea reservoirs. In the first part of phase 4 , cores at $100 \%$ water saturation are being used. Stability of thin gels at Sor will be determined in the second part of the project phase.

\section{Covalent Crosslinker}

\section{Delayed gelation}

NMR and viscosity and filtration measurements $(5 \mu \mathrm{m}$ filter) have been used to characterise gel formation in bulk. Two principles of delayed gelation of covalent systems have been used: method 1) Protection of reactive groups on the crosslinker, and method 2) Delayed action catalysts, where a compound (acid) that will promote the reaction between polymer and crosslinker is liberated at a controlled rate.

The most promising results have been obtained with method 1 and mainly experiments with the polyvinyl alcohol/dialdehyde system have been performed. The crosslinking reaction for the polyvinyl alcohol/dialdehyde is catalysed by acid conditions. Therefore adjusting the $\mathrm{pH}$ is one way of controlling the gelation rate. However, reservoir rock can have very high buffer capacity. Protection of the dialdehyde is therefore an interesting way of controlling the gelation rate.

After an initial bulk screening at $95^{\circ} \mathrm{C}$, two types of protected dialdehydes were selected for further study. The compound 2,2'-trimethylene bis-1,3dioxolane gives delayed formation of glutaraldehyde while 2.5dimethoxy-2.5-dihydrofuran (protected butenedial hereafter called DHF) gives a dialdehyde with an adjacent unsaturation. This dialdehyde may have an other reactivity towards gel formation (stiffer chain).

While the compound 2,2'-trimethylene bis-1.3dioxolane gave little delaye in gelation. the gelation rate was shown to be slowed down significantly by the DHF crosslinker, Table 7. From the studies performed with the three different crosslinkers it looks as if the structure of the dialdehyde (length and stiffness of molecule) used as crosslinker is more important than protection on the aldehyde groups for delaying the gel formation.
The viscometry measurements of the activation energy $\left(E_{a}\right)$ indicate that $E_{a}$ increases with $p H$. The $E_{a}$ using glutaraldehyde and DHF was also measured using ${ }^{1} \mathrm{H}$ NMR (proton NMR). In the NMR measurements the aldehyde proton $\left(\mathrm{O}=\mathrm{C}<_{\underline{H}}\right)$ in the crosslinker has been followed as a function of time during gelation. The NMR measurements gave an activation energy of $65 \pm$ $6(\mathrm{~kJ} /$ mole) for PVA $(2 \%) /$ glutaraldehyde $(5 \mathrm{mM})$ at $\mathrm{pH}$ 3.2 and an $\mathrm{E}_{\mathrm{a}}$ of $118 \pm 18(\mathrm{~kJ} / \mathrm{mole})$ using PVA(2\%)/ DHF $(5 \mathrm{mM})$ at $\mathrm{pH} 3.2$. It is difficult to explain the large difference in activation energy for gelation determined with either viscometry or NMR. However, the activation energy determined with NMR is the activation energy for the reaction between polymer and crosslinker. while $E_{a}$ from viscometry is not based directly on any knowledge about the chemical reaction in the system. Both methods however show that the $E_{a}$ with protected butenedial is significantly higher than with unprotected glutaraldehyde.

Some work has also been carried out using an acrylamide co-polymer (HE300 from Drilling Specialities). In order to delay gel fornation in this system, protected formaldehydes have been tried out at $95^{\circ} \mathrm{C}$ using dimethoxymethane. However, experiments indicate that dimethoxymethane is too stable to decompose into enough formaldehyde for gel formation to take place.

Table 7: $E_{a}$ and gel times for crosslinking of PVA (2\%) with protected (DHF $5 \mathrm{mM}$ ) and unprotected dialdehyde (glutaraldehyde $5 \mathrm{mM}$ ) determined by viscometry.

\begin{tabular}{|l|l|l|l|l|l|l|}
\hline \multirow{2}{*}{$\begin{array}{l}\text { Cross-- } \\
\text { linker }\end{array}$} & $\mathrm{pH}$ & \multicolumn{4}{|c|}{ Gel time (h) } & \multirow{2}{*}{ Ea } \\
\cline { 3 - 6 } & & $95^{\circ} \mathrm{C}$ & $90^{\circ} \mathrm{C}$ & $88^{\circ} \mathrm{C}$ & $82^{\circ} \mathrm{C}$ & $(\mathrm{kJ} / \mathrm{mol})$ \\
\hline$u$ & 3.5 & 1.8 & & 2.1 & 2.4 & 24 \\
\hline$u$ & 4.7 & 11.2 & 13.5 & 14.6 & & 44 \\
\hline$p$ & 3.5 & 10.5 & 14.3 & 17.7 & & 86 \\
\hline$p$ & 4.7 & 165 & 340 & 660 & & 227 \\
\hline
\end{tabular}

u: Glutaraldehyde (unprotected)

p: 2,5-dimethoxy-2.5-dihydrofuran (protected)

\section{Thermal stability at $120^{\circ} \mathrm{C}$}

The degree of syneresis of PVA gels crosslinked with either glutaraldehyde or protected butendial have been studied by gravimetric measurements. PVA (2\%) was crosslinked with 15 and $20 \mathrm{mM}$ glutaraldehyde crosslinker and with 15 and $20 \mathrm{mM}$ DHF. Experiments were performed at $\mathrm{pH} 3$ and $\mathrm{pH} 7$. At $\mathrm{pH} 3$ all the samples show strong synresis. After 30 days less than $30 \%$ of the original mass of gel remain. At $\mathrm{pH} 7$ the stability is better. The trend is a slower development of synresis with the protected crosslinker. A sample of $2 \%$ PVA/ $15 \mathrm{mM}$ DHF at $\mathrm{pH} 7$ showed almost no synresis after 30 days at $120^{\circ} \mathrm{C}$. 


\section{Core experiments:}

Gelation in Berea cores have been studied using both the fast reacting and unprotected glutaraldehyde, and the slow reacting crosslinker DHF. The system consisted of 2\%PVA, $5 \mathrm{mM}$ crosslinker buffered to a $\mathrm{pH}$ of 4.7 using a phosphate / citrate buffer. To detect front plugging by the polymer itself, and attempting to measure the gelation time in the core, the gelant were injected continuously through two cores mounted in series. Effluent $\mathrm{pH}$ and pressure drop across each core were measured. The temperature was $90^{\circ} \mathrm{C}$.

Gel is formed in Berea for both the systems. Using glutaraldehyde as crosslinker gives a gelation time of 4 hours which is lower than determined from bulk experiments. This could be explained by aggregate formation preceding the viscosity increase. Gelation time for the DHF crosslinker exceeded the time of the experiment, which was 200 hours. However gel was formed in the core after increasing the crosslinker concentration to $20 \mathrm{mM}$ and increasing the temperature to $100^{\circ} \mathrm{C}$. No plugging was observed due to the polymer alone. At these conditions the effluent $\mathrm{pH}$ was kept below 5.5 .

\section{Environmental considerations}

An environmental evaluation of the gel systems has been performed. This evaluation includes a literature survey and an experimental screening using Microtox ${ }^{(B)}$ system. Chromium acetate and chromium malonate were also tested on Skeletonema costatum and Acartia ionsa.

The element chromium and its compounds are listed in Annex A of the Paris Convention (Part II) and its offshore use is therefore strictly restricted and controlled. When considering the use of chromium (III) as a crosslinking agent in North Sea reservoirs (Norwegian sector), it is important to be aware of the Norwegian national aim to reduce the discharge of chromium by $70 \%$ in the period 1985-1995 and not to introduce chromium in new applications. Therefore whenever possible. one should consider reduction of the use of chromium by material substitution. However, data was found to support the opinion that regulations concerning human effects should differentiate between the highly toxic and carcinogenic chromium (VI) and the less harmful chromium (III). Chromium (VI) has been shown to be carcinogenic through inhalation and. though there are strong indications that chromium (III) ${ }^{17-21}$ is not carcinogenic, one has to use appropriate protection during handling.

The solubility of chromium is very low at seawater $\mathrm{pH}$ ( $\mathrm{pH}$ of 8.1 ) and the total chromium (both $\mathrm{Cr}^{3+}$ and $\mathrm{Cr}^{6+}$ ) concentration in seawater is nomally in the range among $0.2-0.4 \mu \mathrm{m} / 1^{26}$ and there exists some discrepancy of what the correct ratio of $\mathrm{Cr}^{6+} / \mathrm{Cr}^{3+}$ is in seawater ${ }^{26-28}$.
If high concentration of $\mathrm{Cr}$ (III) is drained into seawater it will probably precipitate rather rapidly and in this way be removed from the seawater. The main concern is whether any dissolved chromium or the newly precipitated chromium on the long term will end up as Cr (VI). Chromium is not among the most investigated trace components in seawater. Consequently the chromium cycle in the marine environment is not fully understood.

The absolute best way to avoid problem related to back production and spill of chromium is to re-inject the produced water. In recent years there has been an increasing interest for re-injection of produced water. Recently the re-injection of produced water was started up on the Ula field. operated by BP.

\section{Toxicity tests}

The Microtox \& system uses lyophilized marine bacteria that emit light upon reconstitution as a bioassay organism and a precision photometer for light measurement. When a toxicant is added the luminescence is diminished. The results are presented as $E_{50}=$ effective concentration, which is the percent sample concentration that produces a $50 \%$ light reduction. The $\mathrm{EC}_{50}$ can be correlated to the $\mathrm{L}_{50}$.

The results indicate that pure polymer components have low toxicity. However, the toxicity increases if biocides are added (e.g. for xanthan and scleroglucan). The toxicity of the crosslinkers is typically higher than the toxicity of the polymer. Crosslinkers as e.g. glutaraldehyde can have rather high acute toxicity (e.g. $\mathrm{EC}_{50}$ $=64 \mathrm{ppm}$ was measured in the Microtox@ test). However, at low concentration, glutaraldehyde is biodegradable. The main concern regarding phenolformaldehyde is the carcinogenic character of formaldehyde.

The acute toxicity of two chromium complexes (chromium acetate and chromium malonate) was tested on the marine algae Skeletonema costatum and on the herbivore Acartia tonsa. The EC50 values for the algae were 24 and $91 \mathrm{mg} / 1$ respectively. The compounds are classified as toxic. For the herbivore the $\mathrm{LC}_{50}$ values were 350 and $>10000 \mathrm{mg} / \mathrm{l}$, respectively and the toxicity is classified as moderate and low. It is uncertain what the effect of the $\mathrm{pH}$ is in these tests. The relevance of these tests is therefore somewhat uncertain, because of the low solubility of chromium in seawater at $\mathrm{pH} 8$. The growth media in the algae test also contains the complexing agent EDTA, which further complicates the matter.

\section{Gel pilot evaluations}

The work has included an evaluation of a gel pilot candidate on the Gyda field. The Gyda field is a deep and hot sandstone reservoir located in the southern part of the Norwegian sector of the North Sea. Due to the high 
temperature, $154^{\circ} \mathrm{C}$, only injector treatment has been considered. The down dip area of the reservoir is divided into an A-sand with permeabilities from $5 \mathrm{mD}$ to 100 $\mathrm{mD}$ and a $\mathrm{B}$-sand with permeabilities ranging from 0.1 $\mathrm{mD}$ up to $5 \mathrm{mD}$. It is assumed to be little or no communication between the A-sand and the B-sand. A detailed description of the field can be found elsewhere 22 .

The cold water injection has resulted in growth of thermal induced fractures (TIF), preferentially in the highest permeable A-sand. The TIF increases the injectivity considerably. The permeability contrast and the TIF result in poor vertical sweep, and most of the oil in the B-sand is left behind after water breakthrough in the A-sand. An early log from in the producer indicated that approximately $98 \%$ of the production came from the A-sand. The main objective was to evaluate whether gel could be used to get more oil from the B-sand.

In the simulation work, a 3D section of the reservoir has been used including two wells. Fracture size and growth was investigated using the BPOPE ${ }^{23}$ simulator. Gel simulations have been performed using Rogaland Research's in-house version of UTCHEM ${ }^{24,25}$. For the gel simulations the fracture is simulated as a static high permeable streak. Temperature simulations showed substantially cooling of the near well area on the injector side. This allows flexibility in polymer selection, but requires a gel system trigged at low temperatures. The low injectivity of the Gyda reservoir implies restriction on the gel system. In core flooding experiments using Gyda cores, a relatively good injectivity for xanthan- and silicate-systems was observed, while HPAM-systems showed poor injectivity in these low permeable cores (5-50 mD). High RRF was obtained with the silicate system.

The strategy was to place a gel in the A-sand from the injector. If the gel was placed just before or after the water breakthrough, the water production from the Asand was reduced and the oil production from the $B$-sand was increased. The oil production from the $\mathbf{B}$-sand was still low due to the low permeability of the B-sand. Simulation works were started to investigate whether TIFs could be created in the B-sand and thereby increase $B$-sand injection and production. At that phase of the project a new PLT survey was performed in the injector showing that scaling probably had occurred in the perforation interval where gelant was assumed to be injected. Consequently the particular injector studied is no longer considered as a candidate. However, a nearby injector (former producer) can be a candidate but at current time the pressure support to the A-sand from this well is still needed. Treatment of this well will not be considered before any water breakthrough from this injector is seen in the nearby producer. When water breakthrough occurs, a complete isolation of the A-sand by cement may also be an alternative.
Two other pilot studies are planned performed in 1995. The first case is high permeability streak problem caused by high permeable channel sand and a producer treatment will be evaluated. For the second field, both a horizontal injector and horizontal producer treatment will be evaluated.

\section{Conclusions}

Temperature stable gels with flexibility in terms of gelation time have been identified and characterised for both metal complex crosslinkers and organic crosslinker.

- By adding carboxylic acid ligands to aluminium or chromium the gelation rate with HPAM can be slowed down to allow for deep emplacement or treatment of high temperature reservoirs. A given gelation time can be obtained by varying either the ligand type or the ligand to metal ratio.

- The gelation time is strongly dependent on $\mathrm{pH}$ and temperature. Determination of the gelation time for a given reservoir should therefore be performed at constant temperature and $\mathrm{pH}$.

- The gelation time increases as $\mathrm{pH}$ increases for the chromium malonate/HPAM system. This is opposite of the trend previously observed for chromium acetate or chromium chloride. and suggests that decomposition of the fully protonised malonic acid is the rate determining step.

- The ligands reduces the tendency for the metals to precipitate, which results in low retention in cores. Also this property allows for deeper emplacement.

- Gelation experiments in cores are very sensitive to the mineral composition. Especially the presence of iron and carbonates requires anaerobic conditions and the use of buffer to avoid uncontrolled $\mathrm{pH}$ increase and polymer degradarion.

- Three low concentration gel systems have shown to persist a high residual resistance factor over a long period at $120^{\circ} \mathrm{C}$ and anaerobic conditions in porous media.

- 2.5-dimethoxy-2.5-dihydrofuran (DHF) as a substitute for glutaraldehyde forms gels with PVA at slower rate than the standard PVA / glutaraldehyde system. The stability experiments at $120^{\circ} \mathrm{C}$ also indicate that DHF as a substitute for glutaraldehyde also improves the stability to some extend.

A new (modified) placement technique is proposed for producer treatments. The method includes the use of a viscous pre flush. The viscous and cold pre flush will give a uniform temperature front. When gelant is injected, it fingers down the high permeable layer. It quickly hits the hot zone, and gels. Gelant injection is stopped before gelant in the low permeable zones reaches the temperature front. The well is put back on production before gel is formed in the low permeable layers. 


\section{Acknowledgements}

This work has been financed and performed as part of the Norwegian RUTH research program. The polymer/gel subprogram is funded by the Research Council of Norway, BP, HYDRO, SAGA, STATOIL, SHELL and TOTAL.

\section{References}

1. Seright R. S.: "Improved Techniques for Fiuid Diversion in Oil Recovery". First Annual Report , US DOE Contract DE-AC22-92BC14880, Oct. 1993.

2. Albonico, P., Bartosek, M., Lockhart, T.P. and Causin, E. "New Polymer Gels for Reducing Water Production in High Temperature Reservoirs", paper SPE 27609 presented at the Production Operation Conference and Exhibition, March 15-17, 1994.

3. Lockhart T.P. and Albonico. P. "A New Gelation Tecriology for In-Depth Placement of $\mathrm{Cr}^{3+} /$ Polymer Gels in High Temperature Reservoirs" paper SPE/DOE 24194 presented at the 8th Symposium on Enhanced Oil Recovery, Tulsa, April 22-24, 1992.

4. Albonico. P., Burrafato, G., Di Lullo, A. and Lockhart. T.P.: "Effective Gelation-Delaying Additives for $\mathrm{Cr}^{3+}$ /Polymer Gels" SPE 25221 presented at the SPE Intl. Symp. on Oilfield Chem., New Orleans, March 2-5. 1993.

5. Bartosek. M., Mennella, A. and Lockhart. T.P. "Polymer Gels for Conformance Treatments: Propagation of $\mathrm{Cr}$ (III) Crosslinking Complexes in Porous Media" paper SPE/DOE 27828 presented at the SPE/DOE 9th Symposium on Improved Oil Recovery, Tulsa, OK 17-20 April 1994.

6. Stavland. A. and Nilsson, S. "Delayed Gelation in Corefloods using $\mathrm{Cr}$ (III)-Malonate as Crosslinker" To be published in Journal of Petr. Scien. and Eng.

7. Matre B. Tenberg-Hansen H. and Tyvold T.: "Gel Systems for High Temperature Reservoirs" paper SPE 29013 presented at SPE Int. Symp. on Oilfield Chemistry, San Antonio, 14-17 Feb., 1995.

8. Moradi-Araghi. A.. Bjornson. G., and Doe. P.H.: "Thermally Stable Gels for Near-Wellbore Permeability Contrast Modifications" SPE Advanced Technology Series, Vol 1. No. 1. pp 140-145. 1993.

9. Albonico, P., Bartosek, M., Malandrino, A., Bryant, S. and Lockhart. T.P.: "Studies on Phenol-Formaldehyde Crosslin ked Polymer Gels in Bulk and in Porous Media". paper SPE 28983 presented at SPE Int. Symp. on Oilfield Chemistry, San Antonio, 14-17 Feb., 1995

10. Moradi-Araghi. A.: "Application of Low-Toxicity Crosslinking Systems in Production of Thermally Stable Gels" paper SPE/DOE 27826 presented at the Ninth Symp. on Imp. Oil Recovery. Tulsa, 17-20 April, 1994.

11 Morgan J.: "State-of-the-art" of Water Shut-Off Well Treatments" paper presented at DTI"s IOR Conference in London, November 10, 1993.

12 Dalrymple, D., Mckown, K.W., and Wood, F.A.:

"Placement Aid for Dual Injection Placement Techniques" Lt. S. Patent, Patent Number: 5.002,127. Mar. 26, 1991.
13 Hight, M.A., Redus, C.L. and Lehrmanii, J.K.: "Evaluation of Dual-Injection Methods for Multiple-Zone Steamflooding" SPERE, Feb. 1992. Page 45-51.

14. Liang, J., Sun, H. and Seright, R.S.: "Reduction of Oil and Water Permeabilities Using Gels" paper SPE/DOE 24195 presented at the Eighth Symp. on Imp. Oil Recovery , Tulsa, 22-24 April, 1992.

15. Conway. M.W., Almond, S.W, Briscoe, J.E. and Harris. L.E. "Chemical Model for the Rheological Behavior of Crosslinked Fluid Systems" JPT, Feb., 1983, pp. 315-319.

16. Lockhardt, T.P. "Chemical and structural Studies of Cr+3/Polyacrylamide Gels" Paper SPE 20998 presented at the SPE International Symposium on Oilfield Chemistry, Anaheim, February 20-22, 1991.

17. EPA Report TR-1242-64A. "The drinking Water Criteria on Chromium", December 20, (1990), (Life Systems, Inc., Cleveland , $\mathrm{OH}$ ).

18. Norseth T., (1980) "Cancer Hazard Caused by Nickel and Chromium Exposure", J Toxicol Environ Health.6. No. 5-6 pp. 1219-1227.

19. Gibb H. J., Chen C. W. and Hiremath C. B., (1988) EPA/600/D-88/129. Environmental Protection Agency, "Carcinogen Risk Assessment of Chromium Compounds".

20. Gibb $H$. and Chen C., (1989) "Evaluation of Issues Relating to the Carcinogen Risk Assessment of Chromium", Science of the Total Environment, 86. No. 12 pp. 181-186.

21. Leonard A. and Lauwerys R. R., (1980) "Carcinogenicity and Mutagenicity of Chromium". Mutation Research, 76, No. 3 pp. 227-239.

22. Rothwell, N.R., Sørensen. A., Peak. J.L., Byskov, K. and McKean, T.A.M.: "GYDA: Recovery of Difficult Reserves by Flexible Development and Conventional Reservoir Management", paper SPE 26778 presented at SPE Offshore Europe Conf.. 1993.

23. Clifford, P.J.. Berry, P.J. and Hongren Gu.: "Modelling the Vertical Confinement of Injection Well Thermal Fractures" paper SPE 20741 presented at SPE 65th Annual Technical Conference and Exhibition, New Orleans. LA, 23-26 September 1990.

24. Stavland. A., Kvanvik. B. and Lohne. A. "Simulation Model for Predicting Placement of Gels" paper SPE 28600 presented at the SPE 69th Annual Technical Conference and Exhibition, New Orleans, LA. 25-28 September 1994

25. Stavland. A.. Ersdal. T., Kvanvik, B., Lohne. A.. Lund. $T$. and Vikane, O. "Evaluation of Xanthan - $\mathrm{Cr}_{\mathrm{r}}$ (III) Gels for Deep Emplacement: Retention of $\mathrm{Cr}$ (III) in North Sea Sandstone Reservoirs" paper presented at the 7th European IOR Symposium in Moscow. Russia. October 27-29. 1993.

26. Bruland K.W.. (1982). Trace elements in Seqwater J.P. Riley, R. Chester (Eds.), Chemical Oceanography Academic Press London, vol. 8.

27. Eldferfield H.: "Chomium Speciation in Seawater" (Earth and Planetary Science Letters 9: 10-16, 1970.

28. Van Der Weijden C.H. and Reith M.: "Chromium(III) Chromium(VI) Interconversions in Seawater", Marine Chemistry, 11(1982), $565-572$. 